\title{
Strategies to improve students' participation and enrich students' leaning of a Fluid Mechanics and Fluid Machinery Course
}

\author{
Sandeep R. Desai \\ Automobile Engineering Department, K.E.Society’s Rajambapu Institute of Technology \\ Shivaji University, Kolhapur, 415414, Maharashtra, India \\ sandeep.desai@ritindia.edu
}

\begin{abstract}
In recent years, the process of teaching learning in the classrooms has changed from traditional mode to the use of collaborative learning techniques. Social media is playing an important role in the society to aware the people about the happenings in the surrounding, exchange information, and to develop interpersonal relations among the people. The present study is an attempt to explore the opportunity to use WhatsApp in order to enhance the students' learning index. The participants in the study were 68 Second Year Engineering students studying the 'Fluid Mechanics and Fluid Machinery' course. The WhatsApp group created for the course was effectively used for interactions of the students with the teachers and peers. The guidelines were communicated to the students to use the group for technical discussions after the working hours. The students were expected to spend one hour in the evening to discuss the concepts taught in the classroom, on the same day. The students were enabled to discuss with the peers and the course teacher on a common platform, to help revise the concepts and get answers for their queries. Additionally, WhatsApp served as the best dynamic tool to share different documents necessary as a part of the teaching-learning process. The impact assessment shows that course results and attainment of course outcomes were considerably improved and initiative helped to establish a better personal connection with the students. The students' feedback indicates that they appreciated the idea and expressed the benefits of forming the group.
\end{abstract}

Keywords: Teaching-learning, Active learning, Collaborative learning, Students' feedback, Course results, Course outcomes

\section{Introduction}

The engineering education is not limited to the use of 'Chalk and Talk' technique in the teaching-learning process. It is the blend of traditional mode and active and collaborative learning techniques. The education today has become student-centric, enabling the teachers to think how students would be engaged, involved, and learn instead of limiting to only physical attendance of students in the classrooms. The activity-based teaching, interaction between the teacher and the students, interaction with the peers and sharing of knowledge resources have become the important elements to make the teaching-learning process meaningful and successful. The teachers have to continuously update themselves and should find out the best ways to engage the students and to meet the students' expectations of enjoyable learning and learning by doing. Communication is one of the vital components in the teaching-learning process to establish the relationship between the teacher and the students. The classroom environment needs to be such that everybody can share, exchange, comment, and discuss to make the learning interesting and to increase the students' participation during the classroom sessions. The personal connection with the students makes a lot of difference as it motivates the students, makes the communication easier, and guarantees positive responses from the students for the number of initiatives/activities planned by the teachers.

These days, Social Media Networks (SMN) is the best and favourite means of communication, interaction, information sharing, and discussion (Bal and Bicen, 2017). There are various means of communication used by the majority of the population, such as emails, messages (SMSs), Facebook, Instagram, Twitter, WhatsApp etc. Looking at the characteristics of these networks and their capabilities to meet the needs of engineering education, the educators have also attracted towards it and started making use of these networks for teaching-learning in engineering education.

\section{A. Motivation for the Study}

The students do not grasp and learn everything that teacher teaches due to lack of participation, lack of interaction with teachers and peers, and unwillingness to revise the concepts after college hours. If the measures are taken in this direction and if an improvement is done in these areas of concern, it is possible to get the intended outcomes of the teaching-learning process. Collaborative learning techniques have the potential to address these issues due to their favourable characteristics. The thinking in this direction had prompted the author to make use of social media platforms such as WhatsApp that has the necessary features to contribute to the effectiveness of the teachinglearning process. WhatsApp has become popular in the last few years due to its user-friendly nature and several benefits that it offers to the users. 


\section{Literature Review}

This section presents the review of the research published in the recent past and identifies the gap for the research on the use of social media in the teaching-learning process. Jamal Abdul Nasir Ansari and Nawab Ali Khan (2020) carried out a survey of 360 students to examine the application of social media and mobile devices. The study revealed that social media used for collaborative learning has an impact on interaction with the teachers and peers and online sharing of the resources. Syamala et. al (2019) discussed the social networking sites and found a gap of knowledge to use social networking sites in the teachinglearning system. Yaviz Bolat (2018) collected the data and analyzed it for teacher candidates' research on the use of social media networks. They found the frequency of the use of social media networks in a day and found the most used social media networks. Erkan Bal and Huseyin Bicen (2017) carried out research on students' social media use and found that social media improves the cooperative learning of the students and makes their communication with the teachers easier. Feridun Ozcakir et al. (2015) reviewed the literature published from January 2005 to March 2015 to examine social media use for educational purposes. The review helped to find the methodology and tools used for data collection and analysis and to get the information on the popularity of different social media platforms. Ozdemir Gol and Andrew Nafalski (2007) have discussed their experiences of using collaborative learning techniques in teaching. The techniques used are group work in the laboratory, short-term course projects and capstone projects. They have concluded that collaborative learning is the best choice for teaching-learning in engineering education.

The research review shows that many researchers have carried out the study to find the application of social media networks in the teaching-learning process and analyzed its impact on the same. The present study is an attempt to test the use of WhatsApp as a social media network and find out its usefulness and impact, instead of using other social media networks such as Facebook, Twitter, Instagram etc. The WhatsApp group is created in order to facilitate better communication, increased interactions, and ultimately to improve students' learning of the course concepts. The course curriculum revision in 2019-20 replaced the two courses with one course i.e. Fluid Mechanics and Fluid Machinery, in the second year first semester of the Automobile Engineering Program. The courses are treated as so-called difficult courses and the difficulty level of the course is further increased when the two courses are combined together. The results of the courses were not satisfactory for the previous academic year. A WhatsApp group was created for the 'Fluid Mechanics and Fluid Machinery' course to make the platform available to the students for discussion during and after college hours. The students can raise the doubts, express their opinions, share information and, connect with the teacher and peers anytime and from anywhere.

\section{Methodology}

The WhatsApp group for the 'Fluid Mechanics and Fluid Machinery Course' was created on $22^{\text {nd }}$ July 2019 i.e. during the first semester of the academic year 2019-20. The discussions on the group were continued until $7^{\text {th }}$ November 2019 i.e. up to the period of end semester examination of the course. The objective of this exercise was to experience collaborative learning in order to enhance the students' learning and subsequently to improve the results. The idea of the WhatsApp group was communicated to the students with the guidelines/rules for participation. The guidelines are given below.

- The students will participate in the group at least on the day on which the lecture is conducted in the class. Thus there will be interaction in the group for at least three days per week.

- The students will participate in the evening on the above mentioned days so that content delivered in the class will be revised on the same day.

- Students can participate in the discussion by typing definitions, expressions, statements, units, descriptions of the concepts etc.

- No content should be copy and paste but it should be typed only. This will make the students first read the content from the resource material and then type it on WhatsApp. This process will enable the students to revise the content and better understand it.

- Personal, non-technical posts and messages other than the course under consideration are not allowed.

- Participation by every student is mandatory and will be highly appreciated.

Apart from the discussion of the important terms and concepts in the course, the group also helped for faster communication of the important instructions to the students and for sharing of resource material or any other relevant information. During the period of examination, the course instructor motivated the students by communicating important tips. The students also raised their doubts based on the difficulty faced while preparing for the examination. The sample of the interactions in the group is shown in Figures 1 to 4 .

Please note that the title of the WhatsApp group seen in the images is 'Theory of Machines' instead of 'Fluid Mechanics and Fluid Machinery'. This is because the images are captured when the same group was renamed as 'Theory of Machines' for the same class, in the second semester of the academic year 2019-20. 


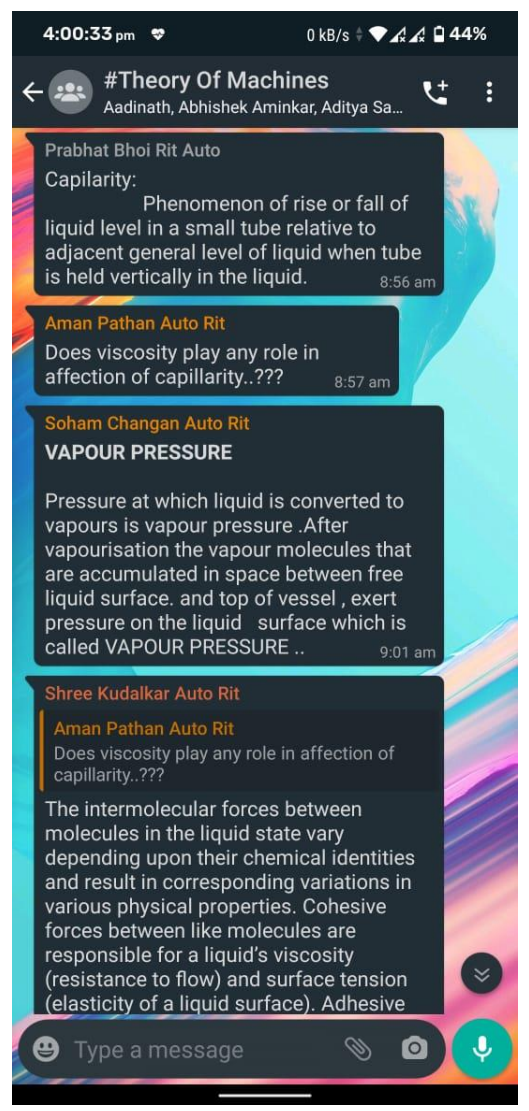

Fig. 1. Sample of the interactions on the WhatsApp group

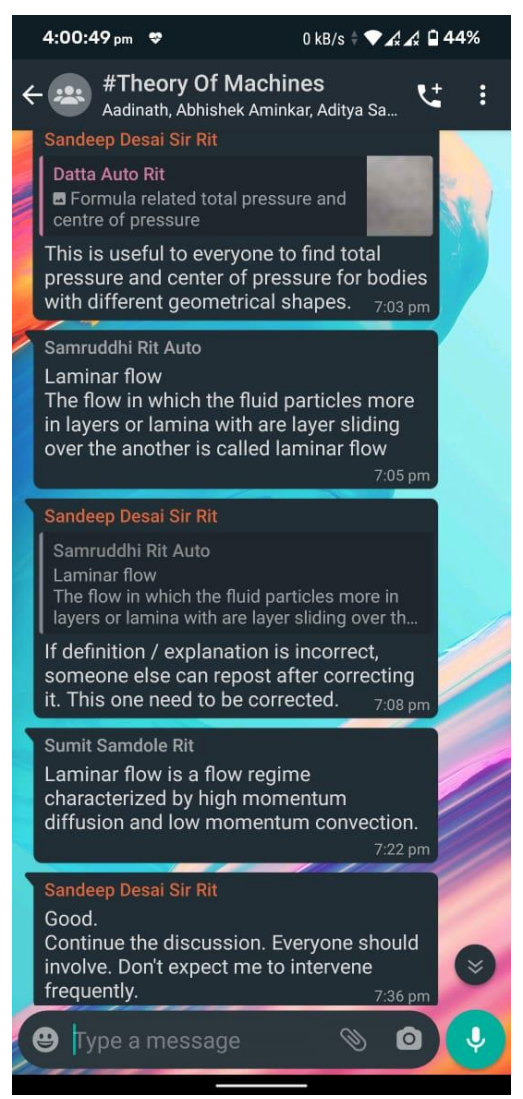

Fig. 2. Sample of the interactions on the WhatsApp group

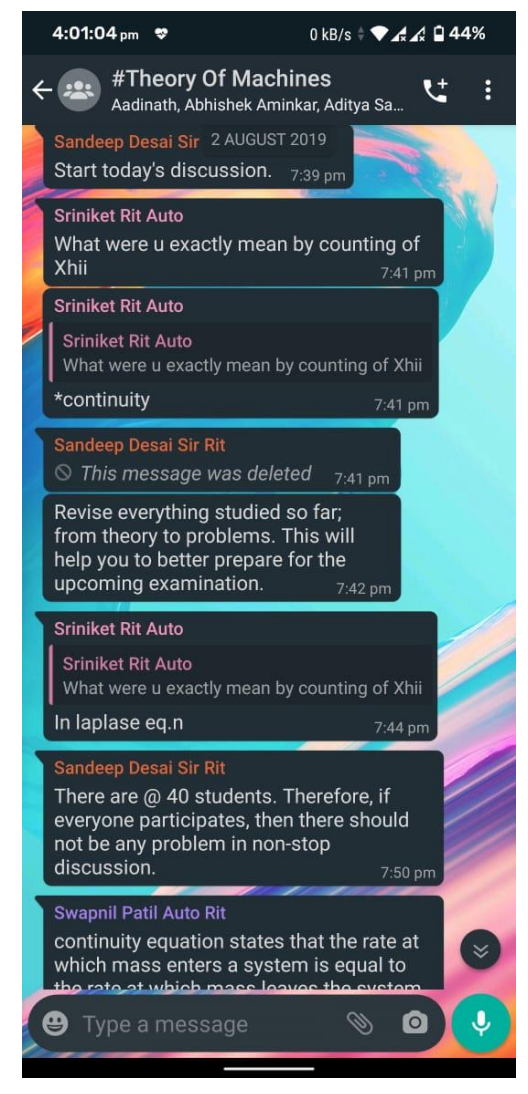

Fig. 3. Sample of the interactions on the WhatsApp group

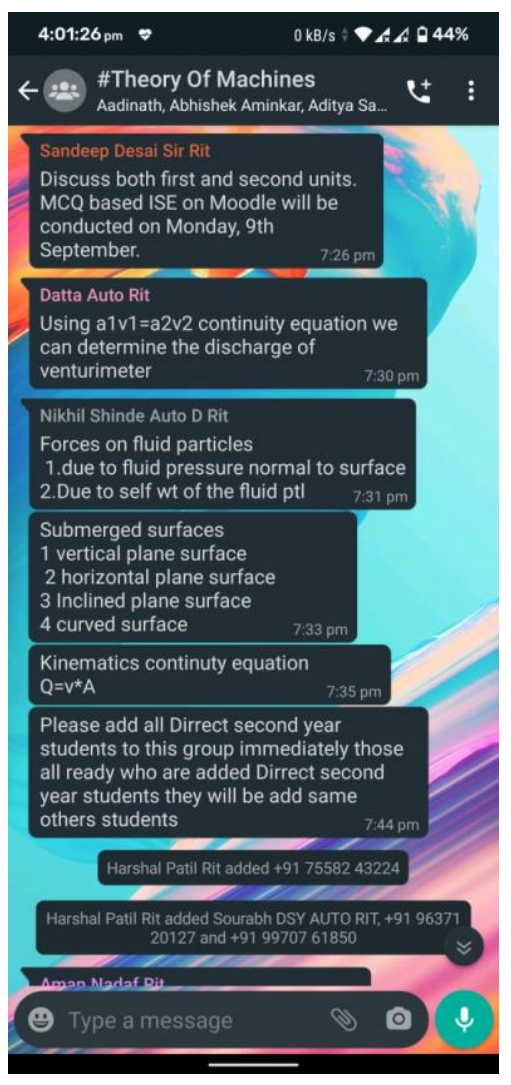

Fig. 4. Sample of the interactions on the WhatsApp group 
Table 1 Feedback Survey (Template)

\begin{tabular}{|c|c|c|c|c|c|c|}
\hline $\begin{array}{l}\text { Sr. } \\
\text { No. }\end{array}$ & Statement & $\begin{array}{l}\text { Strongly } \\
\text { Agree (4) }\end{array}$ & $\begin{array}{l}\text { Agree } \\
\text { (3) }\end{array}$ & $\begin{array}{l}\text { Neutral } \\
(2)\end{array}$ & $\begin{array}{l}\text { Disagree } \\
\text { (1) }\end{array}$ & $\begin{array}{l}\text { Strongly } \\
\text { Disagree (0) }\end{array}$ \\
\hline 1 & $\begin{array}{l}\text { The initiative has helped you to better prepare for the } \\
\text { end semester examination due to a thorough } \\
\text { understanding of the complex concepts in the course. }\end{array}$ & & & & & \\
\hline 2 & $\begin{array}{l}\text { The collaborative learning technique gave you chances } \\
\text { to interact with your peers and learn from them. }\end{array}$ & & & & & \\
\hline 3 & $\begin{array}{l}\text { Overall, you feel that ability has been developed in you } \\
\text { to apply the concepts of Fluid Mechanics for industrial } \\
\text { applications. }\end{array}$ & & & & & \\
\hline 4 & $\begin{array}{l}\text { Do you recommend such a WhatsApp group to be } \\
\text { created for other courses? }\end{array}$ & & & & & \\
\hline 5 & $\begin{array}{l}\text { Please enter your remarks and experiences in brief (one } \\
\text { or two lines). }\end{array}$ & & & & & \\
\hline
\end{tabular}

\section{Measurement of the effectiveness}

The impact analysis of an initiative to create a WhatsApp group has been done using the following tools.

1. Analysis of students' responses to a feedback survey.

2. Comparison of the course results with the previous year's results.

3. Comparison of attainment of Course Learning Outcomes with the previous year's attainment.

\section{A. Analysis of students' responses to a feedback survey}

In order to measure the effectiveness of the initiative to involve the students in collaborative learning through the WhatsApp group, a feedback survey was conducted using Google forms. The survey template is shown in Table 1. Total 43 students have responded to the survey that was expecting the students to respond to the statements on a five-point scale and to express their opinions.

The summary of responses to the statements/questions in the feedback survey is presented in Fig. 1 below.

1. The initiative has helped you to better prepare for the end semester examination due to thorough understanding of the complex concepts in the course.

43 responses

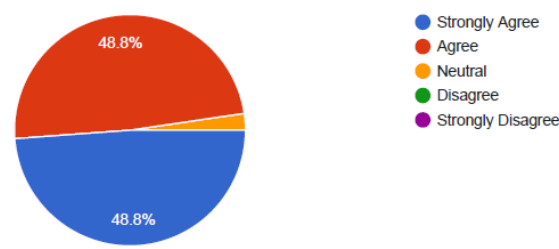

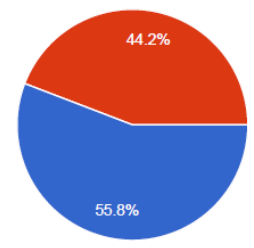

- Strongly Agree

Agree

Neutral

- Disagree

- Strongly Disagree
3. Overall, you feel that an ability has been developed in you to apply the concepts of Fluid Mechanics for industrial applications.

43 responses
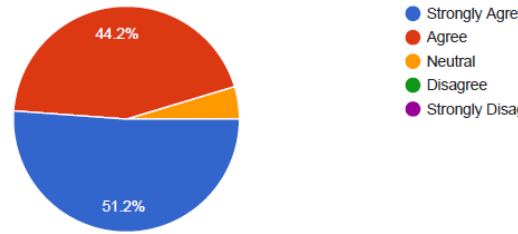

Agree

Disagre

Strongly Disagre

4.Do you recommend such WhatsApp group to be created for other courses? 43 responses

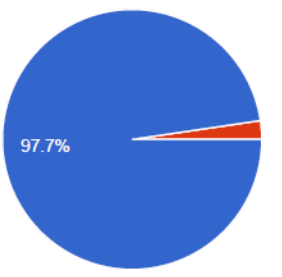




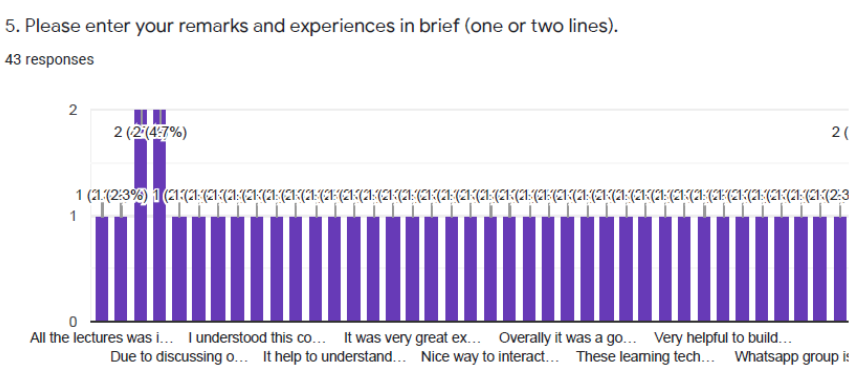

Fig. 5. Summary of the responses to the feedback survey

Please refer to the following link for responses of the students to a feedback survey.

https://docs.google.com/forms/d/11JV5sFY9Kse29vdOk60xdU38gUUVukQIIBGQWddzJI/edit\#respons es

The summary of findings of the students' responses to the statements/questions is presented below.

- $100 \%$ of the students are of the opinion that they got opportunities to interact with their peers and learn from them on a common platform.

- $97.6 \%$ of the students feel that they could better prepare for the end semester examination due to a thorough understanding of the complex concepts in the course.

- $97.7 \%$ of the students recommended that such a WhatsApp group be created for other courses as well.

- $95.6 \%$ of the students agrees with the statement that their participation in the group, involvement in the discussion, and collaborative learning have enabled them to apply the concepts of the Fluid Mechanics course for industrial applications.

- Finally, students' remarks and experiences are summarized as given below.

- Making an official course WhatsApp group is the most needed thing as any quick update, queries, concerns etc. are possible to communicate with ease and comfort.

- It is a very good initiative that helped to make the course interesting.

- It was a different experience of learning using the social platform.

- It is the easier way to interact with the teachers at any time, raise the doubts and get them cleared.

- The platform made it possible to discuss a specific subject rather than all the subjects in one group.

- It is an amazing idea that help the students to clear their doubts and queries due to collaborative learning.
- The course teacher is very kind and supportive and the students learned a lot from him during the course period.

- The course teacher took care of all the students and solved their silly mistakes and doubts.

- The discussion on a group will get closer and clear to the concept

- Very helpful to refresh and remember the concepts taught in the classroom.

- The expectation is to create a WhatsApp group for other courses as well to interact with the students quickly and freely.

B. Comparison of the course results with the previous year results

One of the ways to measure the students' performance in the course is through the formative and summative assessments throughout the semester. The modes of assessment used are; In-Semester Evaluation (ISE), Unit Test-1 (UT 1), Unit Test-2 (UT-2) and End Semester Examination (ESE). Table 2 presents a comparison of the results of the course for academic years 2018-19 and 201920. The course results in the end semester examination were a matter of concern in the previous academic year. The poor course results had ultimately contributed to preventing the students to progress to the next class due to their failure in more than three courses. Thus, the overall passing percentage of the course was also affected during the academic year 2018-19.

Due to the effect of collaborative learning (participation and discussion on the WhatsApp group), the course results of ESE are increased by $64.73 \%$ whereas the average marks in the ESE are increased by $35.65 \%$ compared to the previous year's results. The rise in the average marks obtained by the students in Unit Test-I and Unit Test-II is reported as $5.21 \%$

Table 2. Comparison of the course results

\begin{tabular}{|l|c|c|c|}
\hline \multirow{2}{*}{ Parameters } & \multicolumn{3}{|c|}{ Academic Year } \\
\cline { 2 - 4 } & \multicolumn{2}{|c|}{$2018-19$} & Sem-I \\
\hline Course Title & Fluid & Fluid & Fluid \\
& Mechanics & Machines & Mechanics \\
& & & and Fluid \\
& & & Machinery \\
\hline Average marks in & 15.37 & 15.63 & 10.06 \\
ISE (out of 20) & & & 13.91 \\
\hline Average marks in & 11.95 & 14.49 & \\
\hline
\end{tabular}




\begin{tabular}{|l|l|l|l|}
\hline $\begin{array}{l}\text { UT 1 and UT 2 } \\
\text { (out of 30) }\end{array}$ & & & \\
\hline $\begin{array}{l}\text { Average marks in } \\
\text { ESE (Out of 50) }\end{array}$ & 15.6 & 20.35 & 24.39 \\
\hline $\begin{array}{l}\text { Result of ESE } \\
\text { (passing \%) }\end{array}$ & 42.67 & 60.82 & 85.25 \\
\hline
\end{tabular}

C. Comparison of attainment of Course Learning Outcomes with the previous year's attainment.

The attainment of the Course Learning Outcomes (CLOs) was calculated using different assessment tools (Desai and Patil, 2016). The details of the tools and their weights are shown in Table 3.

Table 3. Details of Assessment Tools for Attainment of CLOs

\begin{tabular}{|l|l|}
\hline Assessment Tool & Weghtage (\%) \\
\hline In-Semester Evaluation & 16 \\
\hline Unit Test-I & 12 \\
\hline Unit Test-II & 12 \\
\hline End Semester Evaluation & 40 \\
\hline
\end{tabular}

In the academic year 2018-19, there were two courses, Fluid Mechanics (Sem-I) and Fluid Machines (SemesterII). In the academic year 2019-20, the courses were combined to have only one-course 'Fluid Mechanics and Fluid Machinery' (Sem-I). The Course Learning Outcomes $\mathrm{CO} 1, \mathrm{CO} 2$, and $\mathrm{CO} 3$ of 'Fluid Mechanics' Course (AY 2018-19) are compared with CO1, CO2, and CO3 of 'Fluid Mechanics and Fluid Machinery' Course (AY 201920). Similarly, Course Learning Outcomes CO3 and CO4 of 'Fluid Machines' Course (AY 2018-19) are compared with CO4 and CO5 of 'Fluid Mechanics and Fluid Machinery' Course (AY 2019-20). The reason is that the statement of the mentioned COs from two years is the same. When the courses are combined, CO4, CO5, CO6 (AY 2018-19, Sem-I) and CO1, CO2 (AY 2018-19, SemII) are not part of the list of COs for the 'Fluid Mechanics and Fluid Machinery' Course (AY 2019-20, Sem-I).

Comparison of attainment of Course Learning Outcomes for academic years 2018-19 and 2019-20 is presented in Table 4. The Course Learning Outcomes (COs) of AY 2019-20 are compared with the respective COs of AY 2018-19. The Course Learning Outcome CO1 is increased by $33.5 \%, \mathrm{CO} 2$ is increased by $38.09 \%$ and $\mathrm{CO} 4$ is increased by $3.86 \%$ compared to COs of the respective course in the academic year 2018-19. The Course Learning Outcome CO3 is decreased by $13.84 \%$ and $\mathrm{CO} 5$ is decreased by $19.14 \%$ compared to COs of the respective course in the academic year 2018-19. The average attainment of the COs for Academic Year 2019-20 is increased by $5.72 \%$ compared to the average attainment of the COs for Academic Year 2018-19.
The poll was conducted on $9^{\text {th }}$ January 2020 on the WhatsApp group to seek the students' opinion on creating

\begin{tabular}{|c|c|c|c|c|c|}
\hline \multicolumn{6}{|c|}{ Academic Year } \\
\hline \multicolumn{4}{|c|}{$2018-19$} & \multicolumn{2}{|c|}{ 2019-20 } \\
\hline \multicolumn{2}{|c|}{ Sem-I } & \multicolumn{2}{|c|}{ Sem-II } & \multicolumn{2}{|c|}{ Sem-I } \\
\hline $\begin{array}{c}\text { Course } \\
\text { Learning } \\
\text { Outcomes }\end{array}$ & $\begin{array}{c}\text { Attain } \\
\text { ment }\end{array}$ & $\begin{array}{c}\text { Course } \\
\text { Learning } \\
\text { Outcomes }\end{array}$ & $\begin{array}{c}\text { Attain } \\
\text { ment } \\
(\%)\end{array}$ & $\begin{array}{c}\text { Course } \\
\text { Learning } \\
\text { Outcomes }\end{array}$ & $\begin{array}{l}\text { Attainm } \\
\text { ent }(\%)\end{array}$ \\
\hline CO-1 & 44 & $\mathrm{CO}-1$ & 73.59 & CO-1 & 58.74 \\
\hline CO-2 & 42 & $\mathrm{CO}-2$ & 58.74 & $\mathrm{CO}-2$ & $\mathbf{5 8 . 0 0}$ \\
\hline CO-3 & 61 & & & CO-3 & 53.58 \\
\hline $\mathrm{CO}-4$ & 51 & CO-3 & 69.14 & $\mathrm{CO}-4$ & 71.81 \\
\hline $\mathrm{CO}-5$ & 27 & $\mathrm{CO}-4$ & 62.97 & $\mathrm{CO}-5$ & 52.85 \\
\hline $\mathrm{CO} 6$ & 48 & & & & \\
\hline \multirow{2}{*}{$\begin{array}{c}\text { Average } \\
\text { Course } \\
\text { Attainme } \\
\text { nt }\end{array}$} & 45.5 & & 66.11 & \multicolumn{2}{|c|}{58.99} \\
\hline & \multicolumn{3}{|c|}{55.80} & \multicolumn{2}{|c|}{58.99} \\
\hline
\end{tabular}

a similar WhatsApp group for the 'Theory of Machines' course in the second semester of the academic year 201920. The sample of the responses to a poll is shown in Fig. 6. The responses to a Poll show that the students have realized the importance of creating a WhatsApp group for the course. They wish to continue such a group for the 'Theory of Machines' course in the second semester. Accordingly, the group for the 'Theory of Machines' course was also created to help the students enjoy collaborative learning.

\section{Conclusions}

The research was carried out to assess the impact of the use of social media platforms (WhatsApp group) on the students' learning index, their involvement in the course, course results, and course outcomes. The WhatsApp group of the students was created by informing the objectives and guidelines to the students at the beginning.

The following conclusions are derived at the end of the study

- It was observed that students' love and inclination towards the use of WhatsApp group has helped to boost their confidence, increase their enthusiasm, motivation level, and participation when it was used for learning.

Table 4. Comparison of Course Learning Outcomes for Fluid Mechanics and Fluid Machinery Course 


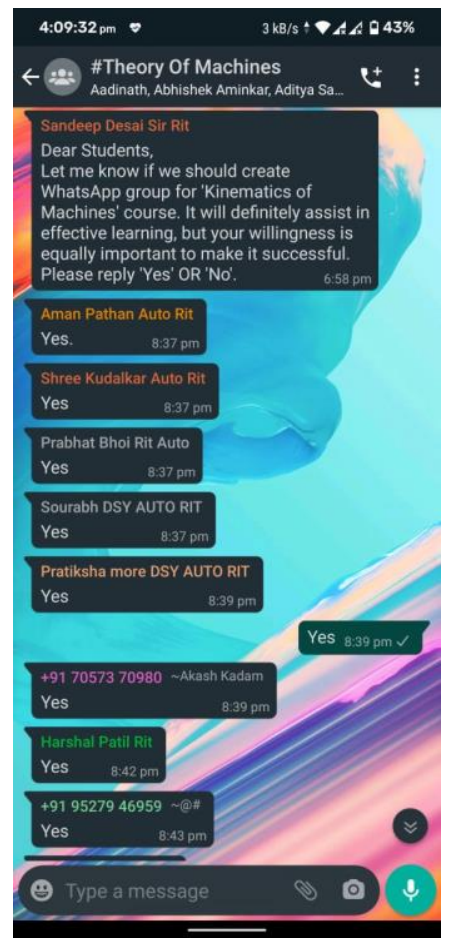

Fig.6. Sample of the responses to a Poll

- The course results that were the matter of concern in the previous year have seen an improvement in the results by $64.73 \%$.

- The attainment of the majority of the course learning outcomes was improved compared to the levels attained in the previous academic year. The average attainment of COs for AY 2019-20 is increased by $5.72 \%$.

- The students' feedback and remarks have helped to conclude that the students were excited to participate in the discussion, interact with their peers and they got an opportunity to get any updates about the course, raise the questions and get the answers for the same.

- Most importantly, the initiative has helped to establish better personal connections with the students compared to other messaging tools such as emails etc.

- Overall, an idea to create a WhatsApp group for a course is an innovative approach to implement collaborative learning in order to increase students' interest in the course and subsequently to improve their performance.

\section{Acknowledgement}

The author expresses his sincere thanks to the Management of Rajarambapu Institute of Technology, Rajaramnagar for the conducive environment, necessary support, and guidance to conduct experiments on the teaching-learning process. The thanks are due to all the students of second-year Automobile Engineering class without the support of whom, it would not have been possible to complete the research activity and get their valuable feedbacks.

\section{References}

[1] Lancioni, R. A. and Chandran, R. (2009) Managing knowledge in industrial markets: New dimensions and challenges, Industrial Marketing Management, 38(2), 148151.

[2] Desai Sandeep and Patil Satyajit. (2016) Design and Execution of the Strategies for effective implementation of Outcomes Based Education in Engineering, Journal of Engineering Education Transformations, 30(1), 111-117

[3] Erkan Bal and Huseyin Bicen (2017) The purpose of students' social media use and determining their perspectives on education, Procedia Computer Science, 120, 177-181

[4] Feridun Ozcakir, Mehmet Fatih Erkoç and Şahine Ozcakir (2015) The Use of Social Media In Education: A Review of Recent Research, International Conference on the Future of Education, 1-7

[5] Jamal Abdul Nasir Ansari and Nawab Ali Khan. (2020) Exploring the role of social media in collaborative learning the new domain of learning, Ansari and Khan Smart Learning Environments, 1-16

[6] K.Syamala Devi, E.Gouthami and V.Vijaya Lakshmi. (2019) Role of Social Media in Teaching - Learning Process, Journal of Emerging Technologies and Innovative Research, 6(1), 96-103

[7] Ozdemir Gol Andrew Nafalski (2007) Collaborative Learning in Engineering Education, Global Jourrnal of Engineering Education, 11 (2)

[8] Shreeranga Bhata, Sathyendra Bhat, Ragesh Raju, Rio D'Souza and Binu K. G. (2020) Collaborative Learning for Outcome Based Engineering Education : A Lean Thinking Approach, Procedia Computer Science, 172, 927-936

[9] Yaviz Bolat (2018) A Research on the Use of Social Media Networks by Teacher Candidates, Journal of Curriculum Teaching, 7(1), 147-157 